\title{
Hemangioma presenting as a painful neck mass: A case report
}

\author{
S Ansari, ${ }^{1}$ K Dhungel, ${ }^{2}$ K Ahmad, ${ }^{3}$ M K Gupta, ${ }^{4}$ R K Rauniyar, ${ }^{5}$ Md. F Amanullah ${ }^{6}$ \\ ${ }^{1}$ Department of Radiodiagnosis, ${ }^{2}$ Department of Orthopedics, B.P. Koirala Institute of Health Sciences, Dharan, \\ Nepal.
}

\begin{abstract}
Hemangiomas of muscles are rare congenital benign vascular tumors usually seen on the trunk and extremities, but can also appear on the head and neck regions. In a young adult with soft tissue attenuation mass in the skeletal muscle, hemangioma should be considered in the differential diagnosis. Ultrasound and computed tomography are the useful imaging modalities for the diagnosing of hemangioma and complete surgical excision is the treatment of choice. We report a case of 24 year old woman with an intramuscular hemangioma involving the posterior neck muscles who presented to our department with painful neck mass.
\end{abstract}

Key words: Hemangioma, vascular tumor, neck mass, ultrasonography, computed tomography.

\section{Introduction}

Hemangioma of soft tissue is a rare congenital benign vascular neoplasm which accounts for less than $1 \%$ of all hemangiomas. They are frequently seen on the trunk and extremities; however up to $20 \%$ of hemangiomas are usually found in head and neck regions. ${ }^{1,2,3}$ It can also be seen in the oropharynx, chin, occiput and neck involving masseter, trapezoid and sternocleidomastoid muscles. Multiple lesions are seen in approximately $70 \%$ of cases. ${ }^{4}$ Men and women are affected with about the same frequency. We report a case of 24 year old woman with an intramuscular hemangioma involving the neck muscles withultrasonographic (USG) and computed tomographic (CT) findings.

\section{Case report}

A 24 year old Asian woman presented with painful posterior neck mass for two months. On palpation, there was a well defined firm mass, not fixed to the underlying tissue in the back of neck. The overlying skin was normal. There was no palpable cervical lymphadenopathy. She was treated symptomatically with non-steroidal anti-inflammatory drugs; but not relieved completely. She was afebrile; her blood pressure and pulse rate were normal. USG revealed a heteroechoic mass of size $3 \times 1.5 \mathrm{~cm}$ with foci of internal calcification and mild internal vascularity in the posterior neck muscles. CT of the neck was done. On noncontrast CT sequences, there was a $3 \times 1.8 \mathrm{~cm}$ low

Correspondence: Dr. Sajid Ansari

E-mail: drsajidansari2012@gmail.com 
attenuation soft tissue mass in the posterior neck muscles with foci of calcifications. On contrastenhanced $\mathrm{CT}$ arterial phase sequences the mass showed mild enhancement and it became isodense on delayed phase. The diagnosis of intramuscular hemangioma was made on the basis of clinical and radiological findings. Patient was operated and the histopathological and microscopic examination revealed vascular channels and prominent mature adipose tissue which was consistent with the diagnosis of hemangioma.

\section{Figure Legends}

\section{Figure 1a and 1b:}

USGimages showing heterogeneous hypoechoic mass with foci of calcifications within in the posterior neck muscles.

\section{Fig. 1,a}

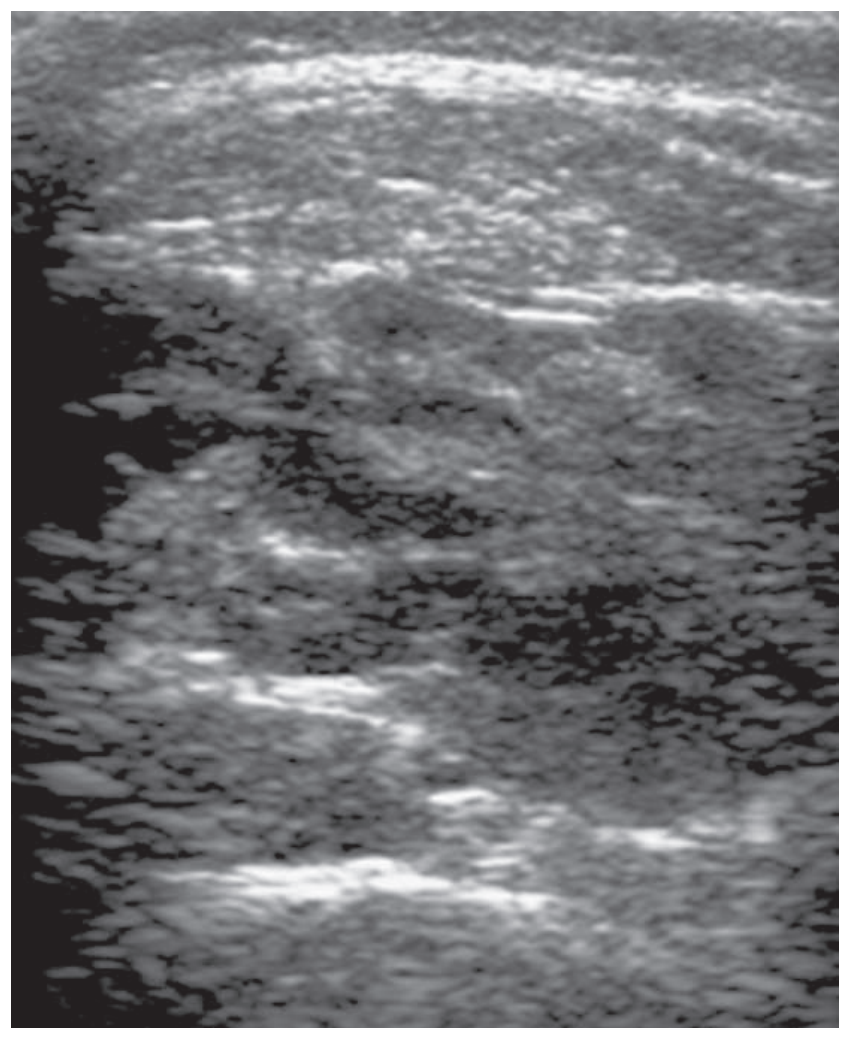

Fig. 1,b

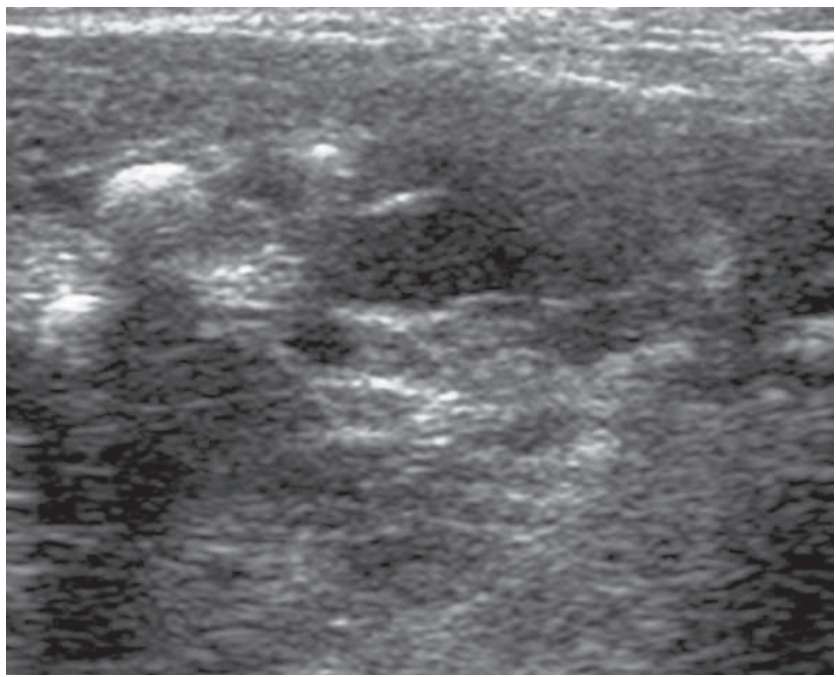

Fig. 2,a

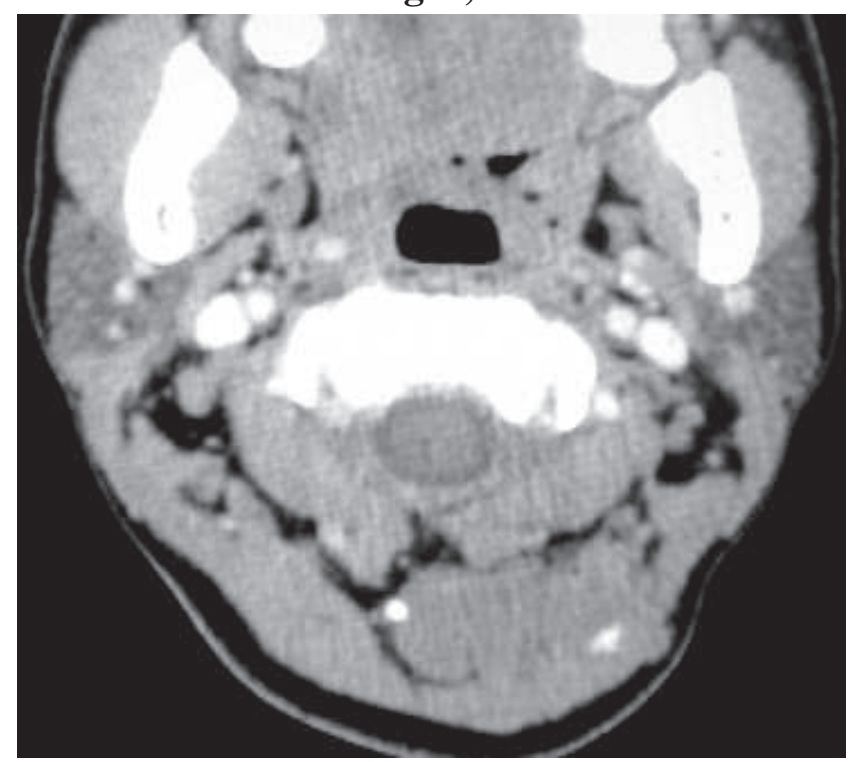

Fig. 2, b

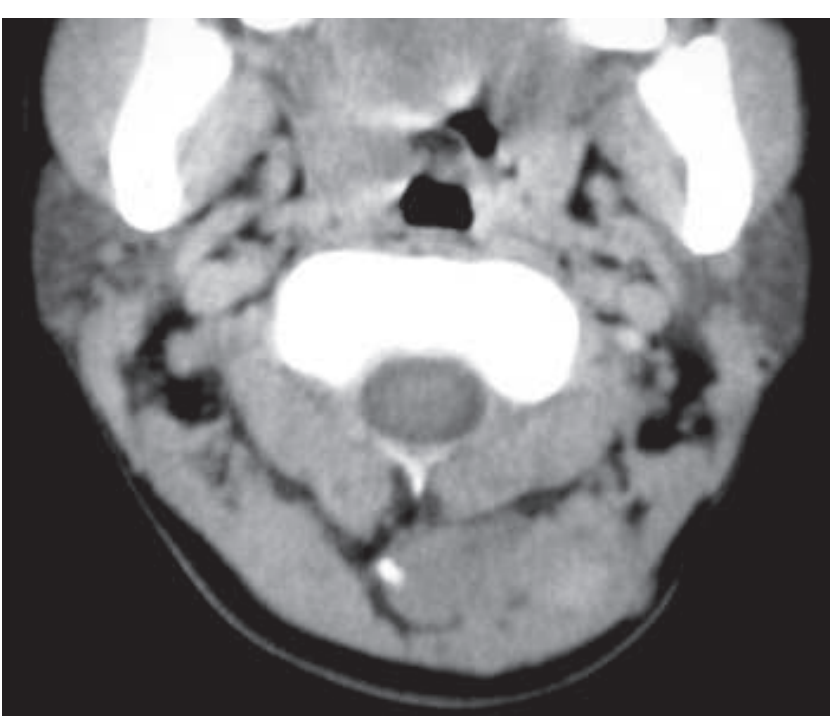


Fig. 3, a

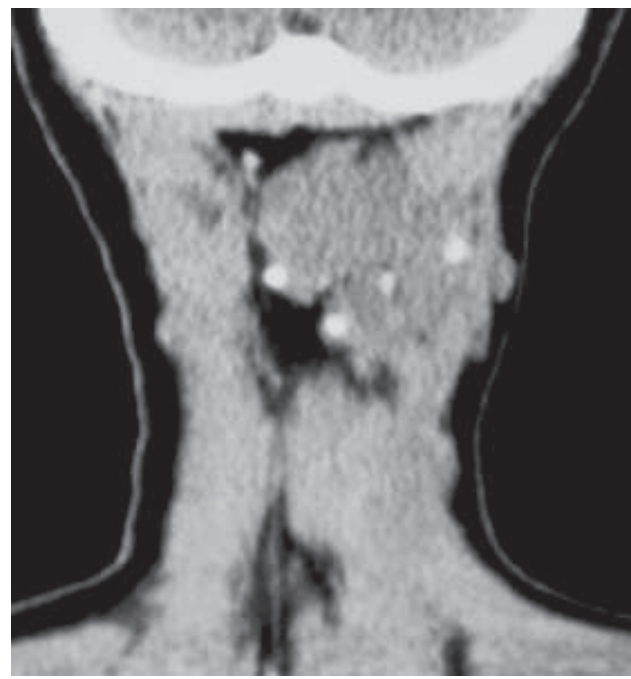

Fig. 3, b

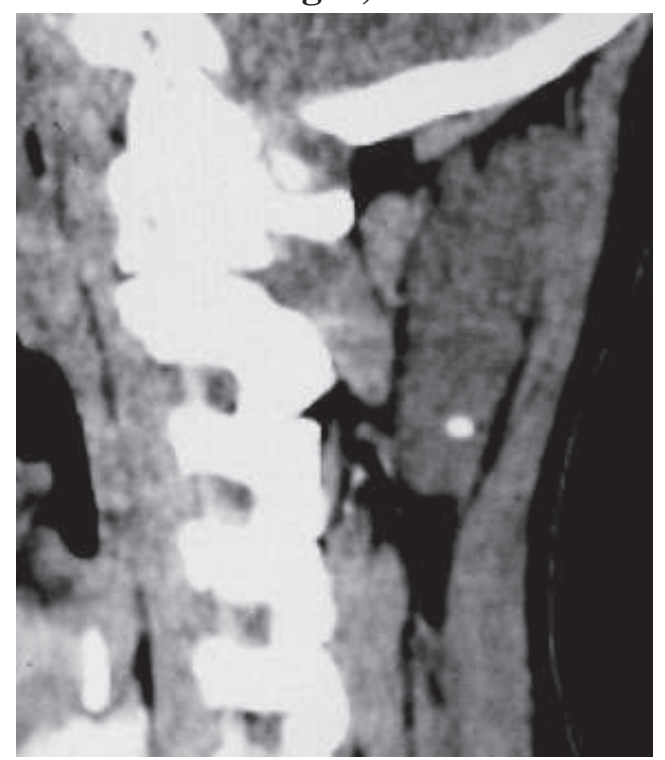

\section{Discussion}

Hemangiomas of the muscles are benign tumor formed due to proliferation of vascular channels with associated variable amounts of mature adipose tissue. They are usually uncapsulated and are locally aggressive tumors. They are usually seen after 2-4 weeks of birth; grows rapidly till the age of 6-8 months and then slowly develop. Involution and spontaneous regression of hemangiomas starts by the age of 5-8 years in 70\% of cases. ${ }^{7}$ It may remain undetected for a long time and there is no malignant potential. They are usually seen in second or third decade of life. In approximately $50 \%$ of cases they are asymptomatic in the first decade; and becomes symptomatic as the tumor grows in the second and third decades. ${ }^{1,3}$ Depending on the vascular structure, hemangiomas are divided into three types i.e. capillary, cavernous and mixed type. ${ }^{3,5,6}$ Thrombus and phleboliths are formed in hemangiomas due to changes in blood flow dynamic. Phleboliths are characteristic of venous or cavernous hemangiomas. Phleboliths may be single or multiple and are seen as round or oval, small radiopacities (calcifications) with central lucency. In the head and neck regions, hemangiomas are uncommonly associated with phleboliths. In our case, it is associated with multiple phleboliths which was an uncommon finding.

USG, CT, Magnetic resonance imaging (MRI) and arteriography are the various modalities used for the diagnosis of intramuscular hemangioma. CT shows enhancing soft tissue attenuation mass with calcific foci within it. MRI shows a poorly defined mass with fatty and vascular components. On MRI, the mass appears as isointense to hyperintense on T1-weighted images and hyperintense on T2-weighted images; however all intramuscular hemangiomas do not show high signal on T2-weighted images. ${ }^{3,6}$ MRI can be used for better localization and size of intramuscular masses. Hemangiomas shows intense enhancement on both CT and MRI due to marked vascularity. Arteriovenous malformations (AVM) and lipomas are the differential diagnosis of hemangiomas. Hemangiomas have internal vascularity and high blood flow velocity which distinguishes it from AVM by the presence of solid parenchymal tissue. On CT, lipomas appear as homogenous and low density masses and are seen in all parts of the body but less commonly seen in the cervical region. 
Hemangiomas can be treated by systemic steroids, intralesional steroid or sclerosant injection, radiotherapy, cryotherapy, vascular ligation, embolization or surgical removal. Complete surgical resection is the treatment of choice. ${ }^{1,3,6}$ However there is $18 \%$ relapse rate after surgery. ${ }^{3,5}$ In case with incomplete resection or recurrence, some researchers recommended adjunctive radiotherapy and/or interferon.

\section{Conclusion}

In a young adult with soft tissue attenuation mass in the skeletal muscle, hemangioma should be considered in the differential diagnosis. Ultrasonography and computed tomography are the useful imaging modalities for the diagnosis and complete surgical excision is the treatment of choice.

\section{References}

1. Afsar FS, Oziz E, Hamdioglu Y et al. Intramuscular hemangioma of the masseter muscle in 9-yearold girl. Acta Angiol 2007;13(1):42-6.
2. Kanaya H, Saito Y, Gama N et al. Intramuscular hemangioma of the masseter muscle with prominent formation of phleboliths: A case report. Auris Nasus Larynx 2008;35(4):587-91.

3. Lee JK, Lim SC. Intamuscular hemangiomas of the mylohyoid and sternocleidomastoid muscle. Auris Nasus Larynx 2005;32:323-7.

4. Calisaneller T, Ozdemir O, Yildirim E et al. Cavernous hemangioma of temporalis muscle: Report of a case and review of the literature. Turkish Neurosurgery 2007;17(1):33-6.

5. Top H, Barcin E. Posttraumatic intramuscular hemangioma of the left temporal muscle. Eur $J$ Plast Surg 2004;27:210-12.

6. Kale US, Ruckley RW, Edge CJ. Cavernous hemangioma of the parapharyngeal space. Indian Journal of Otolaryngology and Head and Neck Surgery 2006;58(1):77-80.

7. Apfelberg DP. Treatment of hemangiomas. In Georgiade GS: Textbook of plastic, maxillofacial and reconstructive surgery. Williams \& Wilkins, 1992:223-29. 